\title{
TINGKAT KEPUASAN KONSUMEN TERHADAP PELAYANAN RESEP DI APOTEK KIMIA FARMA 286 PADANG ASRI
}

\section{(CUSTOMER SATISFACTION LEVEL OF PRESCRIPTION SERVICE IN KIMIA FARMA PHARMACY 286 PADANG ASRI)}

\author{
I N. G. TRI SUTRISNA ${ }^{1}$, PUTU AYU WIDYA GALIH MEGA PUTRI ${ }^{2}$, KADEK DUWI CAHYADI $^{1}$ \\ ${ }^{1}$ Akademi Farmasi Saraswati Denpasar, Bali, ${ }^{2}$ Apotek Kimia Farma 286 Padang Asri, Bali
}

\begin{abstract}
Abstrak: Pelayanan kesehatan yang baik dapat meningkatkan kualitas kesehatan individu. Kesehatan merupakan bagian yang penting guna meningkatkan kualitas hidup dari masing-masing individu. Pelayanan kefarmasian merupakan salah satu bagian dari pelayanan kesehatan. Apotek merupakan salah satu sarana atau tempat pelayanan kefarmasian khususnya pelayanan resep. Apotek Kimia Farma sendiri merupakan apotek yang sudah dikenal oleh masyarakat luas khususnya di Bali dengan pelayanan yang ramah, sikap yang baik, kejelasan, dan ketepatan pemberian informasi yang lengkap, kecepatan dan ketelitian dalam pelayanan. Penelitian tentang tingkat kepuasan pasien terhadap pelayanan resep di Apotek kimia Farma 286 Padang Asri merupakan penelitian deskriptif menggunakan kuisioner yang disebarkan kepada 50 responden yang melakukan pengambilan obat dengan resep di apotek tersebut. Penilaian didasarkan pada 5 (lima) dimensi yaitu dimensi responsiveness (ketanggapan pelayanan), dimensi reliability (keandalan pelayanan), dimensi assurance (keyakinan/jaminan), dimensi empathy (perhatian untuk memahami kebutuhan pelanggan) dan dimensi tangible (sarana fisik, perlengkapan dan pegawai). Dari hasil perhitungan dan analisa data yang diperoleh skor rata-rata pada setiap indikator sebagai berikut indikator responsiveness dengan skor rata-rata 3,14 dengan klasifikasi puas, indikator reliability dengan skor rata-rata 3,13 dengan klasifikasi puas, indikator assurance dengan skor rata-rata 3,28 dengan klasifkasi sangat puas, indikator empathy dengan skor rata-rata 3,17 dengan klasifikasi puas, indikator tangible dengan skor rata-rata 3,19 dengan klasifikasi puas. Secara keseluruhan diperoleh skor rata-rata 3,18 dengan klasifikasi konsumen puas dengan pelayanan kefarmasian di apotek kimia farma 286 padang asri.
\end{abstract}

Kata kunci : kepuasan, konsumen, kuesioner, pelayanan, resep

Abstract: The Good healthcare can improve the health of individual. Health is an important part to improve the quality of life from each individual. Pharmacy services is one part of the health service. Pharmacy is one of the means or tools to get a prescription pharmacy services. Kimia Farma it self is a pharmacy that has been popular by the public, especially in Bali with a friendly service, good attitude, clarity and precision giving full information, speed and accuracy in service. Research on the patient's satisfaction level about care prescription are located in the Kimia Farma pharmacy 286 Padang Asri. The type of study is a descriptive using a questionnaire distributed to 50 respondents who did taking prescription medications at that pharmacy. Ratings are based on 5 (five) dimensions of responsiveness (responsiveness of service), the dimension of reliability (reliability of service), the dimensions of assurance (assurance/guarantee), the dimensions of empathy (attention to understanding customer needs) and the dimensions of tangible (physical facilities, equipment and employees). Base the calculation and analysis of datas are obtained an average score on each indicator as follows responsiveness indicators by an average score of 3.14 with a satisfied classification, reliability indicators by an average score of 3.13 with the classification satisfied, assurance indicators by scores an average of 3.28 with a very satisfied in classification, indicators of empathy by an average score of 3.17 with a satisfied classification, tangible indicators by an average score of 3.19 with the classification satisfied. Overall, we obtained an average score of 3.18 by the classification of consumers are satisfied with the pharmacy services in Kimia Farma pharmacy 286 Padang Asri.

Keywords : consumer, questionnaires, recipes, satisfaction, service.

•email korespondensi: tri_mata05@yahoo.com 


\section{PENDAHULUAN}

Apotek adalah sarana pelayanan kefarmasian tempat dilakukan praktik kefarmasian oleh Apoteker (Kementerian Kesehatan, 2014). Semakin pesatnya perkembangan pelayanan apotek menuntut pemberi layanan apotek harus mampu memenuhi keinginan dan selera masyarakat yang terus berubah dan meningkat (Depkes RI, 2004). Didalam pelayanan resep, pelayanan yang diberikan haruslah bermutu, selain dapat mengurangi risiko terjadinya medication error, pelayanan yang bermutu juga dapat memenuhi kebutuhan dan tuntutan masyarakat sehingga masyarakat akan memberikan persepsi yang baik terhadap apotek tersebut (Harianto, 2005).

Kepuasan konsumen adalah respon yang diberikan konsumen terhadap kesesuain antara tingkat kepentingan sebelumnya dan kinerja aktual yang dirasakan setelah pemakaian (Rangkuti, 2006). Mutu pelayanan dikatakan baik dan memuaskan apabila jasa yang diterima sudah sesuai atau melebihi harapan konsumen. Sebaliknya mutu pelayanan dikatakan buruk atau tidak memuaskan apabila pelayanan yang diterima lebih rendah dari apa yang diharapkan (Kotler, 2000). Berdasarkan hal tersebut, maka dilakukan penelitian melalui kuisioner untuk mengetahui tingkat kepuasan konsumen terhadap pelayanan resep di apotek kimia farma 286 padang asri. Ukuran mutu suatu pelayanan dikatakan baik dapat berdasarkan dimensi tangible (sarana fisik, perlengkapan dan pegawai), dimensi reliability (keandalan pelayanan), dimensi responsiveness (ketanggapan pelayanan), dimensi assurance (keyakinan/jaminan) dan dimensi empathy (perhatian untuk memahami kebutuhan pelanggan) (Ingerani, 2002).

\section{METODE PENELITIAN}

Rancangan Penelitian. Penelitian ini termasuk penelitian observasional. Penelitian observasional adalah penelitian yang tidak memungkinkan peneliti memberikan perlakuan kepada subjek penelitian. Metode pengumpulan data berupa cross sectional yaitu suatu penelitian yang pengumpulan data dilakukan hanya satu kali pada waktu tertentu (Zainuddin, 2011). Lokasi Penelitian ini dilakukan di Apotek Kimia Farma 286 Padang Asri yang dilaksanakan pada bulan Juni 2016.

Populasi dari penelitian ini adalah seluruh pengunjung apotek yang menebus resep di Apotek kimia farma 286 Padang Asri yang memenuhi kriteria inklusi. Perhitungan jumlah sampel yang di ambil adalah sebagai berikut

$$
n=\frac{N Z_{(1-\alpha / 2)^{2}} P(1-P)}{N d^{2}+Z_{\left(1-\frac{\alpha}{2}\right)^{2}} P(1-P)}
$$

Keterangan :

$$
\begin{array}{ll}
\mathrm{n} & \text { : Besar sampel } \\
\mathrm{N} & \text { : Besar populasi } \\
\mathrm{Z}(1-\mathrm{ai}) & : \text { Sebaran normal baku, besarnya } \\
& \text { tergantung tingkat kepercayaan (TK), } \\
& \text { jika TK } 90 \%=1,64, \mathrm{TK} 95 \%=1,96 \\
& \text { dan TK } 99 \%=2,57 \\
\mathrm{P} & : \text { Proporsi kejadian, jika tidak } \\
& \text { diketahui dianjurkan }=0,5 \\
\mathrm{~d} & : \text { Besar penyimpangan; 0,1, 0,05 dan } \\
& 0,1
\end{array}
$$

Dalam perhitungan, untuk menentukan populasi, peneliti menghitung jumlah rata-rata resep yang ditebus di apotek kimia farma 286 padang asri perbulan selama tiga bulan terakhir, jumlah yang didapat sebesar 47,33 resep per bulan.

$$
\begin{aligned}
& n=\frac{N Z_{(1-\alpha / 2)^{2}} P(1-P)}{N d^{2}+Z_{\left(1-\frac{\alpha}{2}\right)^{2}} P(1-P)} \\
& \mathrm{n}=\frac{(47,33) \cdot(2,57)^{2} \cdot 0,5(1-0,5)}{(47,33) \cdot(0,01)^{2}+(2,57)^{2} \cdot 0,5(1-0,5)} \\
& \mathrm{n}=\frac{78,15}{1,66} \\
& \mathrm{n}=47,07
\end{aligned}
$$

Pengambilan sampel dilakukan dengan teknik pengambilan secara Simple Random Sampling.

Instrumen Penelitian. Alat ukur yang digunakan untuk mengukur tingkat kepuasan konsumen terhadap pelayanan resep di Apotek kimia farma 286 Padang Asri, menggunakan kuisioner. Kuesioner yang dibuat berdasarkan dimensi tangible, reliability, responsiveness, assurance dan empathy. Skala yang digunakan adalah skala likert, skala ini mengukur ordinal karena hanya dapat membuat ranking tetapi tidak dapat diketahui berapa kali satu responden lebih baik atau lebih buruk dari responden lainnya didalam nilai skala (Sunyoto, 2011).

Pada kuisioner dirancang pernyataan dengan jawaban yang mendukung (favorable), dan diberikan skor 4 untuk jawaban Sangat Setuju (SS), skor 3 untuk jawaban Setuju (S), Skor 2 untuk jawaban Kurang Setuju (KS), skor 1 untuk jawaban Tidak Setuju (TS). Untuk pernyataan dengan jawaban yang tidak mendukung (un-favorable) 
diberikan skor 1 untuk jawaban Sangat Setuju (SS), skor 2 untuk jawaban Setuju (S), Skor 3 untuk jawaban Kurang Setuju (KS), skor 4 untuk jawaban Tidak Setuju (TS).

Uji Validitas Kuesioner. Uji validitas menunjukkan sejauh mana alat pengukur yaitu kuesioner dapat mengukur apa yang ingin diukur. Jenis uji validitas yang digunakan dalam penelitian ini adalah validitas konstruk yaitu uji validitas untuk melihat konsistensi antara komponen konstruk yang satu dengan lainnya, jika semua komponen tersebut konsisten antara satu dengan yang lainnya maka komponen tersebut valid. Uji validitas dapat dilakukan dengan menggunakan teknik korelasi product moment. Item instrumen dianggap valid apabila hasilnya lebih besar dari 0,3 atau bisa juga dengan membandingkan $r$ tabel (Sugiyono, 2009). Kriteria validasi suatu pertanyaan dapat ditentukan jika:

$r$ hitung > $\mathrm{r}$ tabel, maka pertanyaan yang diajukan dinyatakan valid.

$r$ hitung $<\mathrm{r}$ tabel, maka pertanyaan yang diajukan dinyatakan tidak valid (Riwidikdo, 2012).

Uji reliabilitas kuesioner. Reliabilitas adalah kesamaan hasil pengukuran atau pengamatan bila fakta atau kenyataan hidup tadi diukur atau diamati berkali-kali dalam waktu yang berlainan. Uji reliabilitas dilakukan dengan menggunakan model Cronbach Alpha (Riwidikdo, 2012). Kuesioner dikatakan reliabel jika memiliki nilai alpha minimal 0,6 (Riwidikdo, 2012).

Analisis Data dan Interpretasi Data. Data penelitian yang diperoleh di analisis secara deskriptif. Sistem skoring hasil penelitian menggunakan skala likert dan diklasifikasikan agar lebih mudah diinterpretasiakan dalam rentang ratarata dari nilai terkecil sebesar 1 sampai nilai terbesar 4.

Tabel 1 Klasifikasi Persepsi Konsumen

\begin{tabular}{cc}
\hline Interval & Klasifikasi \\
\hline $\mathbf{1 - 1 , 7 5}$ & Tidak puas \\
$\mathbf{1 1 , 7 5 - 2 , 5 0}$ & Kurang puas \\
$\mathbf{2}, \mathbf{5 0 - 3 , 2 5}$ & Puas \\
$\mathbf{> 3 , 2 5 - 4}$ & Sangat puas \\
\hline
\end{tabular}

(Rahmulyono, 2008)
HASIL DAN PEMBAHASAN

\section{Karakteristik Responden}

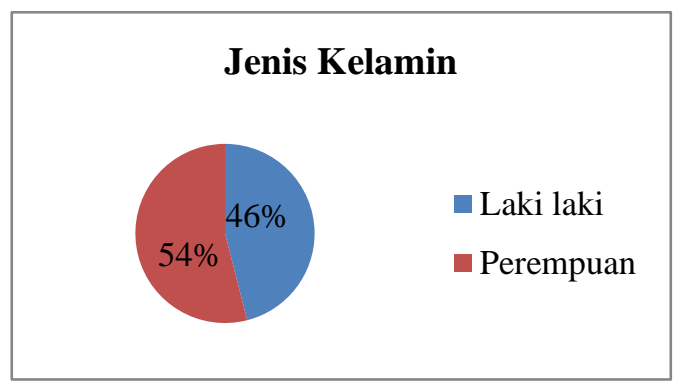

Gambar 3.1 Diagram Karakteristik Responden Berdasarkan Jenis Kelamin.

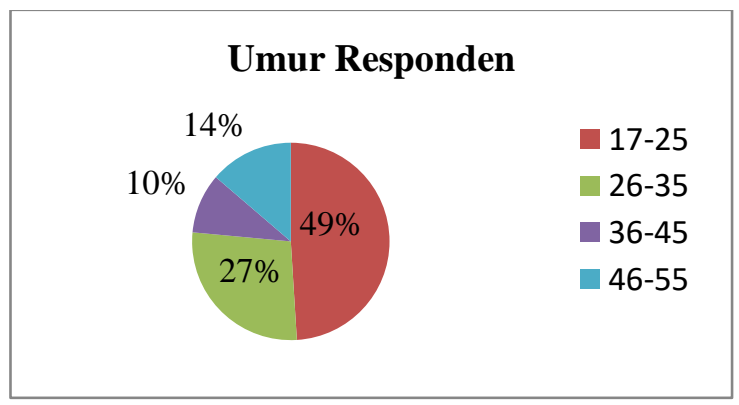

Gambar 3.2 Diagram Umur Responden

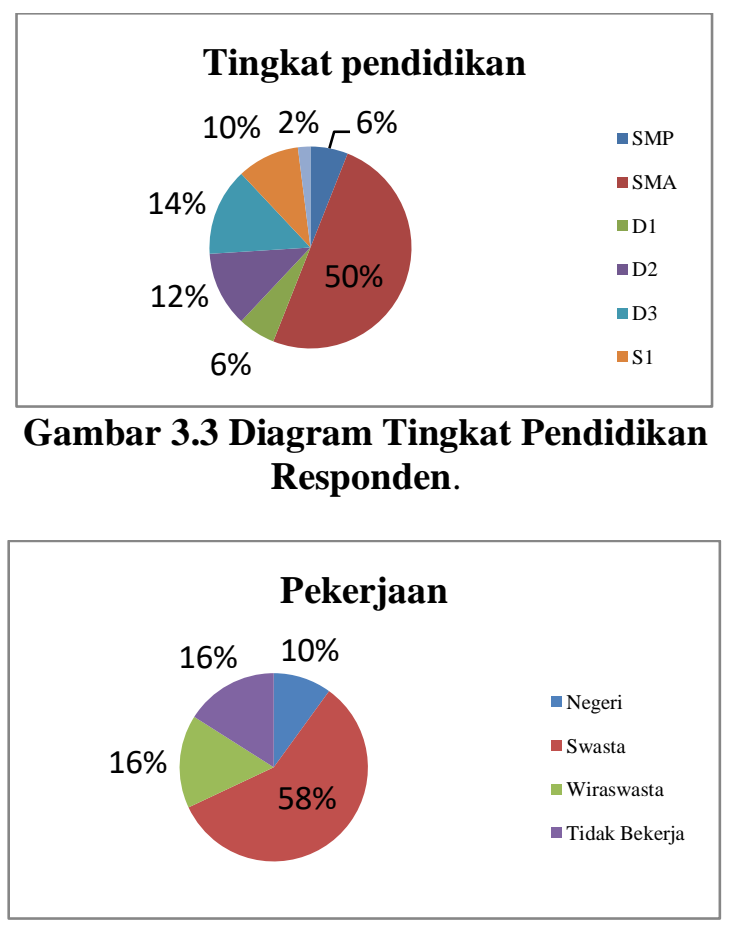

Gambar 3.4 Diagram Pekerjaan Responden 


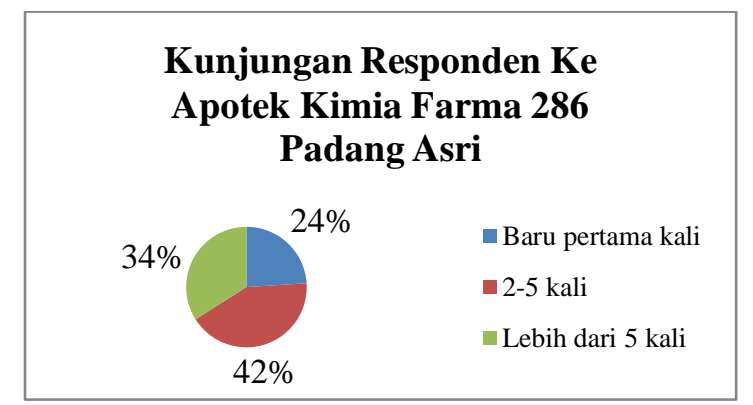

Gambar 3.5 Diagram Kunjungan Responden Ke Apotek Kimia Farma 286 Padang Asri.

Tingkat Kepuasan Konsumen. Berdasarkan nilai skoring yang didapat dari kuisioner pada penelitian ini, skor rata-rata dimensi responsiveness (cepat tangkap) sebesar 3,14 dapat diklasifikasikan konsumen puas terhadap pelayanan resep yang diberikan oleh petugas di apotek kimia farma 286 padang asri. Hal ini sudah memberikan suatu pelayanan yang baik terhadap pasien. Kemampuan daya tangkap dengan pasien dapat ditingkatkan dengan kemampuan untuk memberikan jasa pelayanan yang cepat dan tepat.

Pada dimensi reliability (keandalan) diperoleh skor rata-rata sebesar 3,13 dapat diklasifikasikan konsumen puas terhadap pelayanan resep yang diberikan oleh petugas di apotek kimia farma 286 padang asri. Hal ini menunjukkan hal positif bahwa petugas sudah handal dalam memberikan pelayanan, serta mendapatkan kepuasan karena mendapatkan pelayanan yang sesuai. Keandalan petugas apotek dapat ditingkatkan dengan melaksanakan jasa yang telah disajikan.

Pada dimensi assurance (kepastian) diperoleh skor rata-rata 3,28 di klasifikasikan konsumen sangat puas dengan pelayanan kefarmasian yang diberikan. Hal ini menunjukan segi positif bahwa apotek kimia farma 286 dapat memberikan kepastian kepada konsumen yang menebus resep. Bentuk kepastian dari pelayanan adalah kemampuan petugas dalam memberikan kepercayaan dan kebenaran. Hal ini dapat memberikan motivasi untuk apotek kimia farma 286 padang asri agar tetap mempertahankan keramah-tamahan, kepercayaan, dan keyakinan.

Pada dimensi empaty (empati) diperoleh skor rata-rata sebesar 3,17 diklasifikasikan konsumen puas dengan pelayanan kefarmasian di apotek kimia farma 286 padang asri. Hal ini menunjukkan bahwa apotek kimia farma 286 padang asrisudah memberikan perhatian kepada konsumen. Sikap empati dapat ditingkatkan dengan melakukan komunikasi yang baik, dan memahami kebutuhan yang di perlukan oleh pasien. Berempati terhadap pasien dapat ditunjukkan dengan hal-hal kecil, misalnya memberi salam ketika pasien datang ke apotek, selalu tersenyum, mengucapkan terima kasih saat pasien akan meninggalkan apotek hal ini akan menunjukkan bahwa petugas apotek peduli dan empati terhadap konsumen.

Pada dimensi tangible (berwujud) diperoleh skor rata-rata sebesar 3,19 diklasifikasikan konsumen sudah puas dengan pelayanan kefarmasian yang diberikan di apotek kimia farma 286 padang asri. Fasilitas dalam pelayanan sangat mempengaruhi kenyamanan konsumen. Maka pada dimensi tangible (berwujud) dapat ditingkatkan dengan memberikan fasilitas yang lebih lengkap yaitu dari penampilan fisik apotek, penampilan karyawan, dan alat-alat komunikasi. Misalnya dengan menyediakan fasilitas seperti televisi, tempat duduk, air mineral pada ruang tunggu pasien, sehingga pasien merasa nyaman saat harus menunggu obat selesai disiapkan oleh petugas.

Secara keseluruhan diperoleh skor ratarata sebesar 3,18 diklasifikasikan konsumen puas dengan pelayanan kefarmasian yang diberikan oleh petugas apotek kimia farma 286 padang asri. Kualitas pelayanan resep di apotek ini minimal harus dipertahankan dan ditingkatkan lagi sehingga pasien benar-benar merasa sangat puas terhadap pelayanan resep diapotek kimia farma 286 padang asri. Kepuasan dari konsumen terhadap pelayanan resep merupakan faktor penting untuk mempertahannkan kepercayaan konsumen tersebut. Semakin tinggi tingkat kepuasan pasien makan semakin percaya pasien tersebut terhadap apotek yang bersangkutan.

\section{SIMPULAN}

Tingkat kepuasan konsumen terhadap pelayanan resep di apotek kimia farma 286 padang asri adalah puas. dengan skor rata-rata 3,18 .

\section{DAFTAR PUSTAKA}

Depkes RI. 2004. Keputusan Mentri Kesehatan Republik Indonesia Nomor 1027/Menkes/SK/IX/2004 tentang Standar Pelayanan Kefarmasian di Apotek. Jakarta: Pemerintah Republik Indonesia (Harianto, 2005 
Ingerani, dkk. 2002. Tingkat Kepuasan Pelanggan terhadap Pelayanan Kesehatan di Propinsi DKI Jakarta. Jakarta: Badan Litbangkes.

Kementerian Kesehatan, 2014. Peraturan Menteri Kesehatan Republik Indonsesia No. 35 Tahun 2014 tentang Standar Pelayanan Kefarmasian di Apotek. Jakarta

Kotler, P. 2000.Marketing Management: Edisi Milenium. New Jersey: Prentice Hall. International, Inc. hal. 256-257.

Rangkuti. 2006. Measuring Customer Satisfaction, (Teknik Mengukur dan Strategy
Meningkatkan Kepuasan Pelanggan), serta Analisis PLN JP. Jakarta: Gramedia Pustaka Utama. hal. 19-20.

Riwidikdo, H. 2012. Statistik Kesehatan. Yogyakarta. Mitra Cendikia Press. hal. 104.

Sunyoto, 2011. Analisis Regresi dan Uji Hipotesis. Yogyakarta. CAPS

Zainuddin M. 2011. Metodologi Penelitian Kefarmasian dan Kesehatan. Surabaya: Pusat Penerbitan dan Percetakan Unair. 